\title{
Living Memory Home: Understanding Continuing Bond in the Digital Age through Backstage Grieving
}

\author{
Wan Jou She \\ Weill Cornell Medicine \\ New York, United States \\ wjs2004@med.cornell.edu \\ Chee Siang Ang \\ University of Kent \\ Canterbury, United Kingdom \\ c.s.ang@kent.ac.uk
}

\author{
Panote Siriaraya \\ Kyoto Institute of Technology \\ Kyoto, Japan \\ spanote@kit.ac.jp \\ Holly G. Prigerson \\ Weill Cornell Medicine \\ New York, United States \\ hgp2001@med.cornell.edu
}

\begin{abstract}
Prolong Grief Disorder (PGD) is a condition in which mourners are stuck in the grief process for a prolonged period and continue to suffer from an intense, mal-adaptive level of grief. Despite the increased popularity of virtual mourning practices, and subsequently the emergence of $\mathrm{HCI}$ research in this area, there is little research looking into how continuing bonds maintained digitally promote or impede bereavement adjustment. Through a one-month diary study and in-depth interviews with 17 participants who recently lost their loved ones, we identified four broad mechanisms of how grievers engage in what we called "backstage" grieving (as opposed to bereavement through digital public space like social media). We further discuss how this personal and private grieving is important in maintaining emotional well-being hence avoiding developing PGD, as well as possible design opportunities and challenges for future digital tools to support grieving.
\end{abstract}

\section{CCS CONCEPTS}

- Applied computing $\rightarrow$ Health care information systems; • Information systems $\rightarrow$ Web applications.

\section{KEYWORDS}

Prolonged Grief Disorder, Continuous Bonds, Digital Grieving, Thanatosensitive technology

\section{ACM Reference Format:}

Wan Jou She, Panote Siriaraya, Chee Siang Ang, and Holly G. Prigerson. 2021. Living Memory Home: Understanding Continuing Bond in the Digital Age through Backstage Grieving. In CHI Conference on Human Factors in Computing Systems (CHI '21), May 8-13, 2021, Yokohama, Japan. ACM, New York, NY, USA, 14 pages. https://doi.org/10.1145/3411764.3445336

Permission to make digital or hard copies of all or part of this work for personal or classroom use is granted without fee provided that copies are not made or distributed for profit or commercial advantage and that copies bear this notice and the full citation on the first page. Copyrights for components of this work owned by others than ACM must be honored. Abstracting with credit is permitted. To copy otherwise, or republish, to post on servers or to redistribute to lists, requires prior specific permission and/or a fee. Request permissions from permissions@acm.org.

CHI'21, May 8-13, 2021, Yokohama, Japan

(c) 2021 Association for Computing Machinery.

ACM ISBN 978-1-4503-8096-6/18/06 . .\$15.00

https://doi.org/10.1145/3411764.3445336

\section{INTRODUCTION}

Almost everyone will experience the loss of a loved one at some point in their lives. For those in mourning, specific 29 cognitive, emotional, behavioral, and social responses are normal and natural [8]. When symptoms of grief persist at intense levels after a year post-loss, these symptoms have been associated with significant distress and dysfunction (e.g., suicidal ideation, poor sleep, depression and anxiety, problems at work and home). We have advanced diagnostic criteria now recognized by the ICD-11 and DSM- 5 for Prolonged Grief Disorder (PGD) [66, 67]. PGD is characterized by the symptoms of intense yearning, disbelief, feeling emotionally numb, lack of acceptance of the death, mistrust of other people, and a decreased sense of self [67]. The point prevalence of PGD beyond six months post loss has been estimated to be 10-15\% [28, 47]. Furthermore, suicidality, sleep disorders, physical illnesses, depression, anxiety, and substance use disorders are associated with meeting diagnostic criteria for PGD [6, 67]. At its core PGD is an attachment disturbance - separation distress evoked leaves mourners alone, miserable and detached from others and the world around them.

The problem is further compounded by the barriers some people may face in accessing the appropriate channels to mourn the passing of their loved ones; this may be due to mobility constraints (e.g. home bound patients with severe health conditions) or legal mental health act restrictions (e.g. patients in secure psychiatric care).

As digital technologies have become commonplace, many bereaved people now use social media, personal blogs and other websites to express their feelings and thoughts when they mourn, and wish to memorialize their lost loved ones digitally [1] [36]. They are often engaged in activities such as posting on the website of the deceased, expressing yearning for and missing them, seeking guidance from the deceased, trying to "communicate" with and honoring them, recalling fond memories, uploading photographsvideos or creating online websites to commemorating the deceased [35]. These practices are now considered by many researchers as a form of continuing bonds in the digital era. [1,35, 36].

Continuing bonds are ongoing relationships between the bereaved and the deceased [39]. Researchers have also described the continuing bonds as unilaterally continuing relationship of the bereaved with the deceased [77]. Due to the broadness of this definition, many different experiences in the mourning period have been 
regarded as continuing bonds. For example, experiences such as seeing the deceased, hearing their voice, feeling their touch physically, using or keeping their possessions, having a dream of them, looking at the photographs, visiting the cemetery, talking to them, going to places they used to go, adopting the personal characteristics of the deceased and acting like them, taking them as a role model, feeling the influence of the deceased on their current identity, thinking about what they would have done while making a decision, are considered as continuing bonds experiences [18, 19, 78]. Despite the increased popularity of virtual mourning practices, there is little research looking into whether continuing bonds maintained digitally promote or impede bereavement adjustment.

Using Living Memory Home (LMH, a custom-made web-based application to honour the deceased person's memory) as a digital probe, supported with in-depth semi-structured interviews, we examined how bereaved visitors to the LMH managed their private, intra-personal grieving. Our aim was to explore design opportunities and challenge to facilitate backstage grieving, helping people to continue bonding with the deceased as a way of coping. The LMH is based on the idea that maintaining a continuing bond through posting and interacting with a website $[1,35,36]$ in which the bereaved person honors the deceased relative by sharing photographs, music and other memories, is therapeutic (i.e., associated with reduction in intensity of symptoms of PGD).

\section{RELATED WORKS}

Pursuant to Massimi and Charise's introduction of thanatosensitivity in technology [51], designing technology for the end of life and grief has become the subject of a group of HCI researchers $[11,25,48,60,71,87]$. In the past decade, subsequent interest fields include methods to manage and archive digital legacy [11, 48, 61], utilizing technology to remember and pay respect to the deceased $[55,62]$ and mediating the emotional bonds with the deceased [25]. In addition to the studies in HCI field, some clinical researchers such as Wagner et al. [84], Litz et al. [45] and She et al. [75] further examine the implementation of technology in internet-based cognitive behavioral therapy or grief self-help. The primary outcomes of some of the studies suggest that involving technology can potentially facilitate better intervention outcomes but require active engagement of the therapists or larger scale assessment of its efficacy. More works are certainly needed in validating the previous findings and further enhance the tools.

There is a large and growing literature on bereavement from the sociological, psychological and anthropological perspectives. This literature has touched on topics such as the impact of death on relationships with kin [32], the idea of "social death" with an emphasis on culturally acceptable ways for people to grieve [74], as well as psychological processes following the death of a loved one [42]. Of relevance to the present study is the research examining the important role of physical objects, as well as the private and public space in which these objects are spatially organised in supporting processes of memorializing the deceased [29,54]. Research has highlighted the communicative, spatial and physical values [34] of memorial places and objects, designed for the bereaved to express their grief, remember the deceased and receive support from the community.
Given the pervasiveness of digital technologies in almost all aspects of our everyday life, there is an increasing interest in the emergent use of the internet to honour and memorialize deceased loved ones. As a result, a key research direction of $\mathrm{HCI}$ studies of death and bereavement is the investigation of how digital technology is appropriated and used to remember and honor the deceased, with an emphasis on understanding commemoration via computer-mediated communication as well as people's relationship with digital artefacts in the process of grieving. Early studies $[64,76]$ reported the use of online forums and chat rooms as virtual spaces for social support for the bereaved, where people share stories about their deceased loved ones. More recently, driven by the goal to explore new possibilities in technology design to enable people to be more expressive in engagement with online bereavement tools, empirical work involving surveys and in-depth interviews has been carried out to understand how bereavement is experienced in the context of digital technology $[50,64]$. These studies highlight the direct way digital technology has been used to support bereavement, by bringing friends and families from many geographically dispersed locations to "remember together, even when apart." More interestingly, they also provide design directions for technologies currently used by living people to consider how people will be represented digitally after their deaths, to better facilitate the grieving process of surviving families and friends. Following these, social networking sites such as Facebook have implemented "post-mortem" profile features, providing a personal archive of the deceased, as well as a virtual space for online memorial practices. Brubaker and Callison-Burch 2016 outlined three approaches to post-mortem digital profile management: i) Configuration-Based: enables users to make decisions pre-mortem about what the system should do after their deaths; ii) InheritanceBased: transfers ownership of digital artifacts from the deceased to an heir; iii) Stewardship-Based: focuses on the responsibilities to care for the deceased loved one and the grieving community.

Among these approaches, technology inheritance is perhaps the most studied within the $\mathrm{HCI}$ community, where researchers contrast and compare inheritance of digital artefacts with their physical counterparts, shed light onto issues such as digital persistence, and how technology can be designed to gain sentimental value as this inter-generational digital heirlooms is passed down across multiple generations [38]. Designers of such technology will need to consider issues regarding the tension between "public vs private" data, and the "physical vs virtual" nature of the technology. Researchers also point to the importance of 'personalization' of artifacts (e.g. unique handwriting vs generic typing) which make them more meaningful and valuable to the bereaved [50].

Given the sensitive and personal design space required of online tools addressing bereavement, some HCI researchers have argued for a value-driven design approach to understand the ethical, cultural and socio-technical issues in designing technologies for the bereaved [20]. There is research on supporting mourners in difficult times through smart physical objects, following the 'Ubiquitous Computing' design paradigm, such as "tilting picture frames" and "mourning stones" which communicate family commemoration across time and space [82]. These projects focused on developing technologies for "implicit communication" between mourners to create a sense of togetherness in the bereavement process in a culturally acceptable manner. Furthermore, research has extended the 
work in lifelogging [24], which helps individuals to capture and reflect on their life experiences, in order to support "afterlife" logging for the bereaved. This allows friends and families to appropriate the logged data to support reflection, mourning, and commemoration.

Although emerging studies in HCI have examined user and design challenges of digital technology for bereavement, to the best of our knowledge, there is currently no research of which we are aware that examines how maintaining bonds using digital technology relates to the intensity of grief of bereaved people, i.e. how and if such technology help people cope with grief. Of course, reminiscing is important to the mourners, but it is unclear whether the "continued bonds" is always appropriate, as a psychological goal in grieving is to reach "closure", i.e. coming to terms with the fact that the deceased is no longer alive.

Furthermore, most research in digital mourning has so far focused on so-called "frontstage" grieving, i.e. rituals/practices which involve observances and/or other participants, such as funerals (virtual or physical), memorials and storytelling with friends and families, etc. A great deal of grief management happens backstage where individuals who are grieving often isolate themselves so as to grieve alone. In the era of social media, what would have been backstage in the past may well become frontstage in forms of (semi) public Twitter or Facebook posts. The horrible details of a suicide, the dislike of the deceased by some people, the conspiracy that a family member was responsible, or whatever private information or speculation can quickly spread and known by many. This is the unpleasant consequence when a member of the audience inadvertently enters the backstage. Therefore, we need to ensure that people have an outlet for backstage as well frontstage grieving digitally, in order to facilitate positive continued bonding experiences. Current HCI studies explored digital tools which help people invoke the intimate bonds of social relationships [60], yet it remains undetermined how and indeed whether continuing bonds and rituals experienced in the context of digital technology promote the understanding of loss, reduce symptoms in the mourning process and facilitate adjustment.

\section{METHODOLOGY}

\subsection{Study Procedure}

In this study, we recruited participants from those who had lost their loved ones in the last 3 years and asked them to use the Living Memory Home (LMH) for a one-month period. We excluded individuals who were under 18 years of age and did not live in the New York Metropolitan area. This was necessary to ensure that participants would have access to local mental health referral services during the study if needed. In addition, participants who were vulnerable (e.g., prisoners, pregnant women, children or any other group of users that might be especially vulnerable and require special consideration) or exhibited suicidal ideation were also deemed ineligible for the study. To recruit participants, flyers were posted around a medical university hospital in the US and around residential buildings in the surrounding area. Participants who requested to participate in the study were invited to the center for a pre-screening interview. A bereavement researcher and mental health professional carried out the pre-screenning process and assessed the suicide risk of the participant (using questionnaires such as the PG-13 to assess grief intensity [67]). Afterwards, the researcher explained the purpose of the study, gave instructions on how the LMH could be used and addressed participants' questions prior to them signing the informed consent form. Participants were also told that during the study, they would receive a weekly follow-up call from a mental health professional to monitor their emotional well-being. If the participant became severely distressed as a result of study, a project member would reach out to evaluate the situation and provide the participants with the contact information of a study-affiliated mental health professional to ensure that they receive the psychological care they need.

After agreeing to enroll in the study, each participant was asked to complete a 1-month session with the LMH that included 7 days of mandatory login during the first week and afterwards a 3 week period where they were able to use the system freely. In the first 7 days, participants were required to set up their memorial space in the LMH and answer at least 2 question prompts in the writing exercise. There were in total 7 sets of question prompts that were designed to elicit participants' memories about the deceased loved ones (e.g., "My most treasured memory of you is...") and encourage them to explore the different types of memories (e.g., "What I have always wanted to tell you is..."). At the end of the study, semistructured interviews were conducted with the participants. The topics which were covered in the interviews are described in detail in section 3.4. Participants who complete all the study activities received $\$ 100.00$ as compensation. Overall, the study was carried out over a period of 6 months and ethical approval was granted by the Institutional Review Board at [a private research university in the USA] (IRB Number 1810019629). To ensure data security, the system went through extensive vulnerability testing and the data was stored on a HIPAA-compliant server (a server which implements strict technical safeguards to prevent unauthorized access and provides data protection for sensitive patient data according to the Health Insurance Portability and Accountability Act in the US)

\subsection{Participants}

A total of 24 participants had initially enrolled in the study. 4 of the participants had dropped out before completion. This left 20 participants who completed the clinical study of LMH. Overall, 9 participants were male and 11 were female. The average age of the participants were $42($ Mean $=41.9, \mathrm{SD}=18.79)$ years. 17 participant had lost a family member, 2 lost a relative and 1 participant lost a friend within the last 24 months. Based on the PG-13 questionnaire [67] that was administered in the pre-screening stage, 4 participants experienced PGD (Prolonged grief disorder) symptoms based on the PG-13 score threshold of 30, and 16 participants experience the normal level of grief as indicated by their PG-13 score (Mean=23.25, $\mathrm{SD}=8.77)$. After the 1 month period of using the application, 17 users agreed to participate in the interviews. The characteristics of these 17 participants are shown in Table 1.

\subsection{Study Apparatus: The Living Memory Home Web Application}

We developed the Living Memory Home (LMH) web application with the aim of providing people in grief with a virtual place where they could continue their bond with the deceased by honoring, 


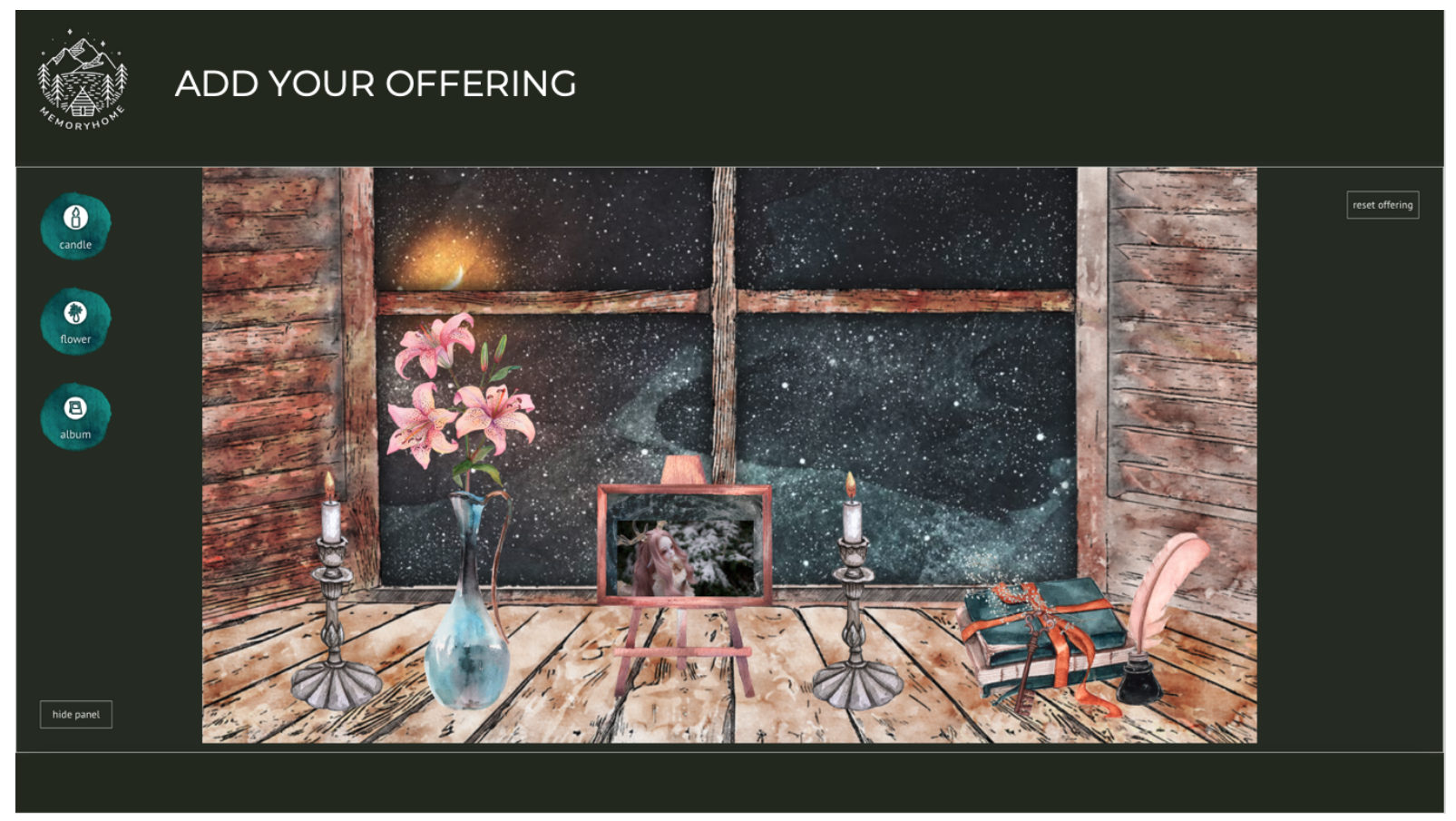

Figure 1: Living Memory Home memorial space.

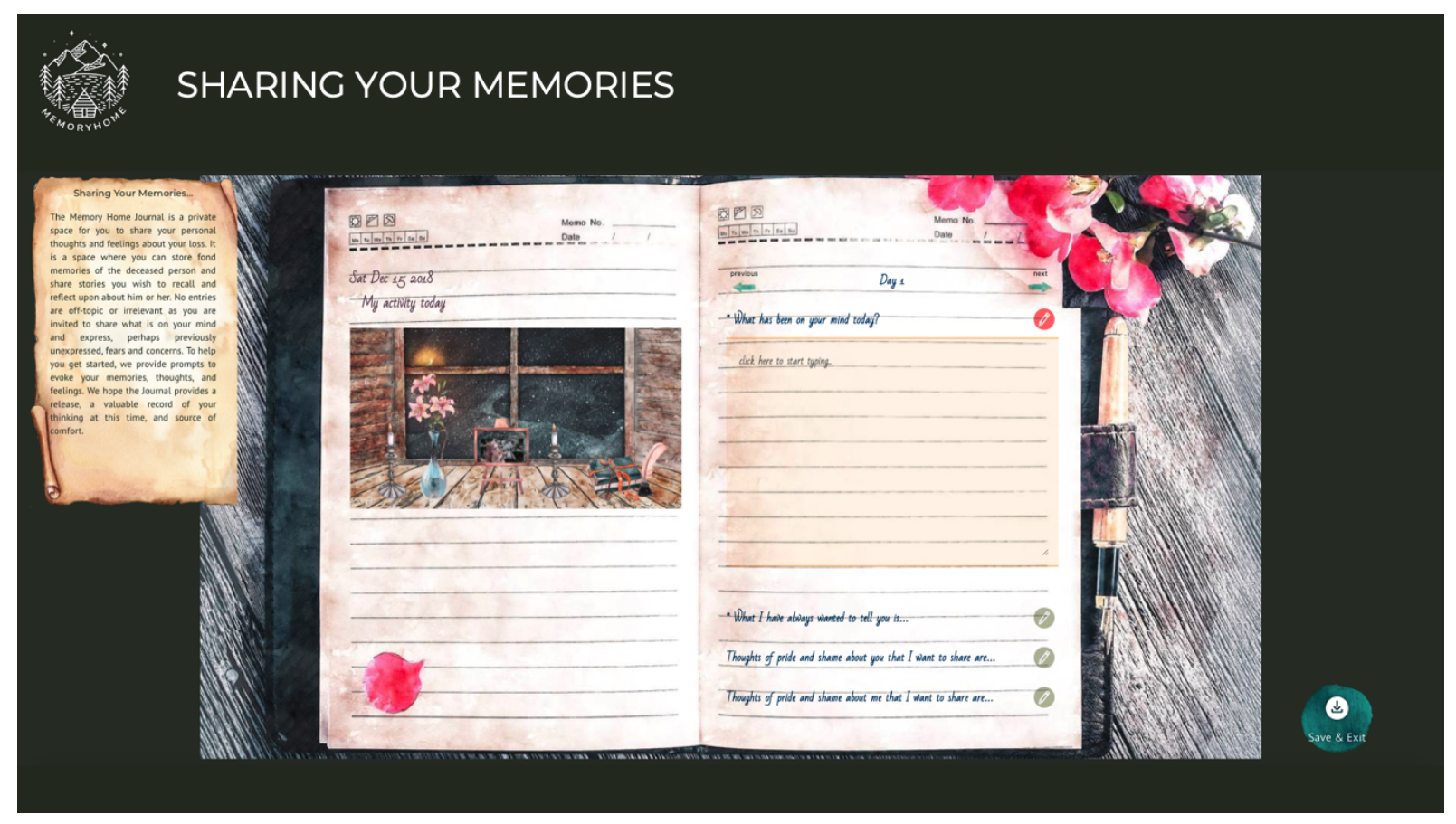

Figure 2: Living Memory Home writing exercise. 
Table 1: The Demographics and characteristics of the participants

\begin{tabular}{|c|c|c|c|c|c|}
\hline Participant ID & Age & Gender & Ethnicity & Person(s) Lost & $\begin{array}{l}\text { Experience with tech in the grief con- } \\
\text { text }\end{array}$ \\
\hline 2 & 22 & Male & Asian & Older brother & Not applicable \\
\hline 6 & 60 & Female & White & Mother & $\begin{array}{l}\text { Used phone calls. Feels social media is } \\
\text { ingenuine. }\end{array}$ \\
\hline 7 & 68 & Male & White & Mother & $\begin{array}{l}\text { Used Facebook to announce the loss and } \\
\text { obtain support }\end{array}$ \\
\hline 8 & 69 & Female & White & Mother & $\begin{array}{l}\text { Posted on a blog and obituary website. } \\
\text { Thought social media was inappropriate } \\
\text { for grief. }\end{array}$ \\
\hline 9 & 56 & Female & White & Father \& Mother & $\begin{array}{l}\text { Uploaded photos and wrote on a blog. } \\
\text { Posted messages on Facebook. }\end{array}$ \\
\hline 10 & 41 & Female & White & Mother & $\begin{array}{l}\text { Not applicable. Preferred to keep it for } \\
\text { herself }\end{array}$ \\
\hline 12 & 34 & Male & Asian & Friend & $\begin{array}{l}\text { Posted photos of the lost one's travels } \\
\text { on social media }\end{array}$ \\
\hline 13 & 35 & Female & Hispanic or Latino & Father & $\begin{array}{l}\text { Posted photos and songs on Facebook } \\
\text { and received support from friends and } \\
\text { family. }\end{array}$ \\
\hline 15 & 39 & Male & White & Fiance & $\begin{array}{l}\text { Visited the deceased's Facebook page } \\
\text { and posted photos and videos. }\end{array}$ \\
\hline 16 & 34 & Male & Asian & Mother & $\begin{array}{l}\text { Not applicable. Did not feel the need to } \\
\text { share }\end{array}$ \\
\hline 17 & 25 & Female & Asian & Grand father & $\begin{array}{l}\text { Posted photos to make a story on Insta- } \\
\text { gram. Felt neutral and no help by doing } \\
\text { so. }\end{array}$ \\
\hline 19 & 52 & Male & $\begin{array}{l}\text { African American } \\
\text { or Black }\end{array}$ & Mother & $\begin{array}{l}\text { Posted messages on Facebook and felt } \\
\text { good to know he had support }\end{array}$ \\
\hline 20 & 31 & Female & White & Grand mother & $\begin{array}{l}\text { Not applicable. Did not want to disclose } \\
\text { loss online. }\end{array}$ \\
\hline 21 & 22 & Male & Hispanic or Latino & Father & $\begin{array}{l}\text { Not applicable. Did not need support } \\
\text { from people he was not closed to }\end{array}$ \\
\hline 22 & 59 & Female & White & Brother & $\begin{array}{l}\text { Put up a memorial website for people to } \\
\text { post on it. Post messages on Facebook } \\
\text { and felt comforting when people com- } \\
\text { mented with supportive messages. }\end{array}$ \\
\hline 23 & 65 & Female & Hispanic or Latino & Father & $\begin{array}{l}\text { Contacted siblings and share photos } \\
\text { and videos using WhatsApp. Hoped to } \\
\text { have more technology to support pri- } \\
\text { vate grief. }\end{array}$ \\
\hline 24 & 66 & Male & $\begin{array}{l}\text { African American } \\
\text { or Black }\end{array}$ & Step mother & $\begin{array}{l}\text { Preferred to share grief with family and } \\
\text { friends verbally. Felt too much informa- } \\
\text { tion was shared on Facebook. }\end{array}$ \\
\hline
\end{tabular}

memorializing and reminiscing about them. Overall, the LMH was created through a co-design process that incorporated feedback from 4 multidisciplinary experts with research experience in grief study, mental healthcare and medical application development and stakeholders who had experienced the loss of a loved one. The activities and features of LMH (e.g. writing exercises, digital mourning space) were created based on best practices drawn from bereavement and grief literature (e.g., Neimeyer's Techniques of Grief Therapy [56] and Litz's internet-based grief intervention in applying constructs of Cognitive Behavioral Therapy [45]) which were further refined based on the expert's field experiences. In the LMH, users would have the opportunity to create his/her own space where he/she could upload and "decorate" it with photographs, notes and shared memories of the deceased and related memorabilia. This was designed to provide a controlled continuing bonds environment, as a place where the bereaved user can engage in digital rituals related to their loss, express emotions and thoughts and pay respects to the deceased. By memorializing the deceased, the $\mathrm{LMH}$ aims to 


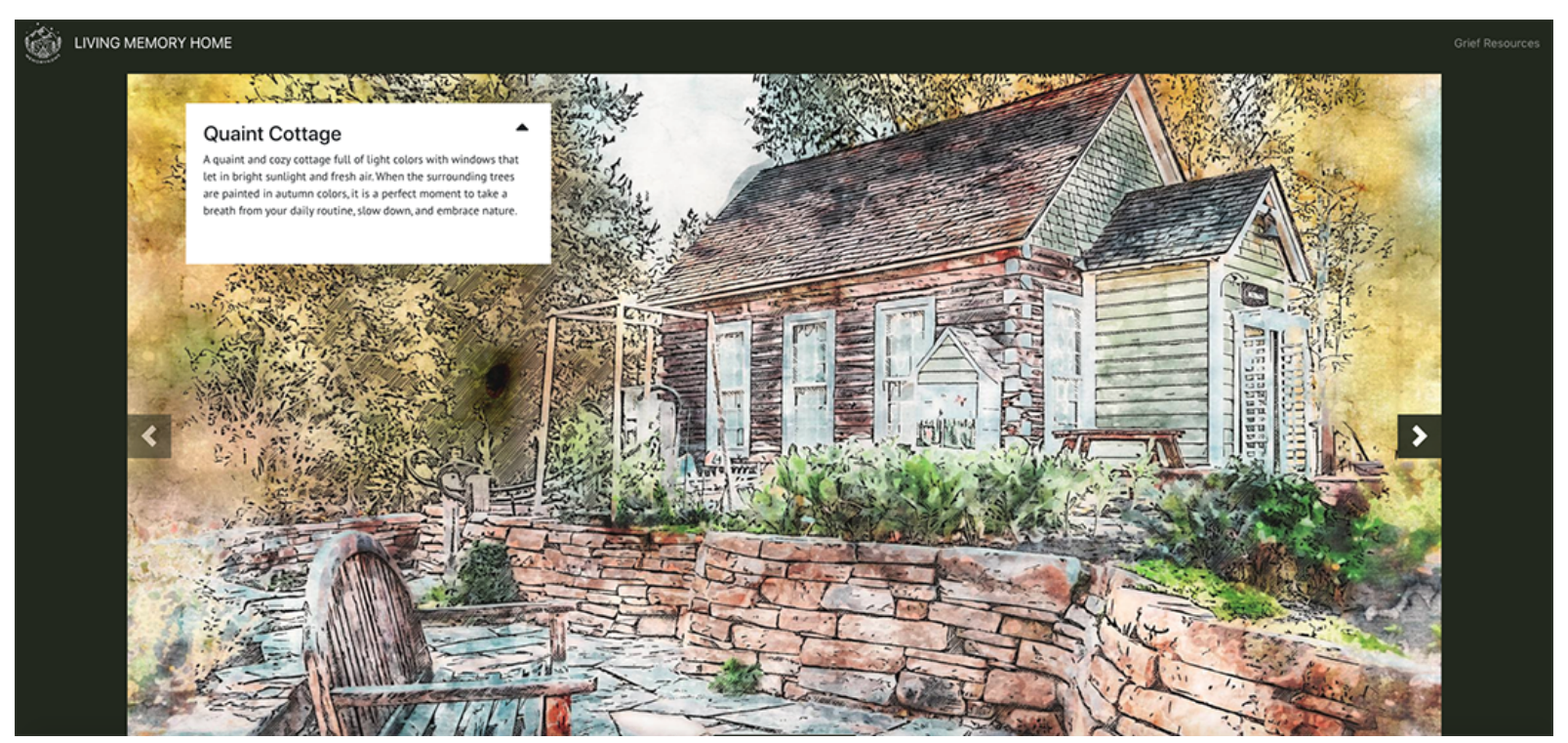

Figure 3: Living Memory Home selecting home base exercise.

alleviate the common concern among bereaved individuals that they will forget their loved ones.

There are two major components in the Living Memory Home, the Memorial Space and the Desk. The Memorial Space was designed as a peaceful and private space where the bereaved user can engage in rituals to pay respect to the deceased. Users could decorate the space with candles, flowers and the photo of the deceased The Desk was designed to provide a journaling space, with the left "page" showing the memorial activity logs of the user and the right "page" showing question prompts related to the participants' relationship and the thoughts they might have towards their deceased loved ones. Figure 1 shows the screenshot for the memorial space and Figure 2 shows the screenshot of the Desk page. Finally, Figure 3 shows the screenshot for the virtual home selection page.

\subsection{Data Collection and Analysis}

The semi-structured interviews were conducted by a researcher who was an expert on grief research. The interview was divided into three major parts: (1) questions aimed at understanding the participants' general experiences of grieving on the internet, (2) questions aimed at gathering insights into how participants use LMH to conduct backstage grieving activities and (3) questions which asked participants about the implications of LMH usage on their grief intensity, continuing bonds and emotional well-being.

The researcher began the interview by asking participants to describe their grieving behaviors on the internet and the digital instruments or websites that they had used to facilitate their grieving process. Afterwards, participants were asked about their general experiences in using the LMH through open-ended questions. Researcher then prompted participants to describe their experiences of using the two main components, the Memorial Space and the Desk. The questions included open-ended usability questions derived from Post-Study System Usability Questionnaire (PSSUQ) [22], questions related to their emotional status while using LMH and their feedback about the content of the journal prompts. At the end of the interview, participants were asked about their grief intensity and perception of continuing bonds with the deceased after using the LMH. The researcher also proactively asked them to assess whether the LMH contributed to or detracted to their emotional well-being and whether there were aspects of LMH that could be beneficial or harmful for mourners like them. During the interviews, audio recording was carried out and notes were taken. In total, we obtained approximately 17 hours worth of interview data.

The audio recordings from the interviews were then transcribed and anonymized. Thematic analysis (a qualitative method frequently used for identifying, reporting and interpreting the repeated patterns of people's opinions, views or experiences [9] ) was used to analyze data from the interviews. Two expert HCI researchers and one medical researcher collaboratively coded the transcripts. As part of the thematic analysis process, codes which exhibited similar patterns were then grouped together and themes were generated from the recurring code groups. The coders reviewed and critically discussed the themes and the underlying codes together until an agreement was reached on the final themes and we refined the codes and themes until saturation had been achieved. Overall, four themes emerged from our analysis and are presented with quotations from participants in the paper.

\section{RESULTS}

Through a thematic analysis, we have identified four themes of digital mourning that takes place mostly backstage in a private space, helping people to continue bonding with the deceased as a way of coping. The themes are: i) Grief as a private affair, ii) Control the negative grief narrative, iii) Linking the past to the present and iv) Digital "Pensieve". In each theme, we describe our key observations, through the lens of existing literature and theories about death and mourning. We place specific emphasis on the 
backstage nature of our observations, and discuss the implications of this to the emotional well-being of the grievers.

\subsection{Digital grieving as a private affair}

Dealing with grief often requires the bereaved to continually reflect on and reconfigure their personal relationship with the deceased, come to terms with their loss and re-establish a meaningful sense of self [91]. Throughout the interviews, participants frequently highlighted the importance of having a place where they could quietly mourn and reflect on their loss and freely express their emotions and thoughts towards the deceased without the concern of being observed. While the role of social media and web-based memorials in providing a digital frontstage avenue for the "collective mourning and remembrance for the deceased" has been well documented in literature [10,35], the results from our study showed that for some participants, a key part of the grieving experience remains a private affair and that the public nature of social media platforms do not always cater to their emotional needs for backstage grieving in the digital era.

While social media allow users to easily share the grief experience and exchange messages of condolences [52], their very nature as a (semi) public space makes it easy to overshare messages of support, sometimes leading to users to feel that their loss may have been trivialized. As grief is considered an intimate affair for each individual, the perceived casualization in which supportive messages are so quickly and effortlessly exchanged on social media makes them seem disingenuous [83]. There is therefore an inherent conflict between the slow process of grieving and healing, and the ephemeral "here today, gone tomorrow" nature of social media interactions. As a result, participants would rather reflect on their loss either alone in a private setting or with the support of close family members and friends.

I guess personally, I don't really need support from people that I'm not really that close with. Like just to hear things from people online, Oh, I'm so sorry for your loss. Things like that. I don't really need to hear that from people that aren't super close to me. (Participant 21, 22 Male, Lost Father)

Basinger et al [4] describe how bereaved individuals tend to develop a sense of ownership in their grief and establish personalized privacy rules to govern how they share information about their loss. Some participants expressed their avoidance of extreme emotions and uncomfortable interactions in the public space:

We tend to, you know, verbalize it and express it among family, friends and members and stuff like that rather than going on Facebook and, you know, broadcast it all over the world. (Participant 24, 66 Male, Lost Step Mother)

Indeed, social media are by and large designed to nurture a positive community in which excessive display of negative emotions, especially those in the low arousal spectrum (e.g. miserable, ashamed, as opposed to high arousal negative emotions such as angry) is frowned upon [83]. While this design intention is understandable, it has resulted in our participants shying away from expressing their emotions openly and seeking emotional support from their loved ones on social media. As such, users often self-edit the messages they wish to convey to their loved ones in such public venues and self-censor their emotions on such platforms.

It's not private, right? So there's always that thought that it's going to be read by someone and, you know, so there's always potentially going to be this like self editing and restriction (Participant 9, 56 Female, Lost father and mother)

These observations underline the challenges some users face when "interacting" with the deceased in digital public spaces. On a social platform, users are unable to take full ownership in the memory and identity of their loved ones as they have been shaped by the community. In addition, they found it difficult to fully control the narrative of how their loved ones would be remembered. As such, the virtual representation of the deceased in these frontstage spaces run the risk of being depersonalized [41].

The importance of a private grieving space is further illustrated by the way participants talked about customizing their virtual mourning space through the LMH. In some cases, participants used the customization tool (e.g. to select and decorate their virtual cabin and choose an appropriate view) to select an environment which was related to their loved one to commemorate them (e.g. selecting a place which they felt they would have enjoyed).

I did choose [this view] because he used to love going to mountains...I like it that it was kind of associated with him because he was the person who would always like to go on a mountain and all this hiking and forest. (Participant 12, 34 Male, Lost Friend)

However, to our surprise, we also observed participants who chose to create a quiet and relaxing virtual space as a separate area from their daily life where they could be alone. Instead of constructing a virtual space that assumes the role of a "virtual cemetery" which acts as a marked representation of the deceased (playing a similar role as cemeteries in the physical world [92]), some participants created a space that act as a "virtual sanctuary", a personal place which they feel emotionally safe, calm and relaxing that would allow them to bond with their lost loved ones. The virtual representation of these spaces help provide the ambience that encourages peaceful self reflection and allows users to contemplate the intimate issues involving their loved ones.

Uh, I love to come to, and I think cabins, have very warm places that you can relax. So it's a good place for you to relax and to think and to mourn, you could. if you have to laugh, you can laugh, have to cry and cry. So I liked that environment. (Participant 23, 65 Female, Lost Father)

the cabin....is kind of in a separate area based, you'll be able to see the city out there...the candle and the quietness. So to me that was a, it gives you that environment for you to be in touch with yourself. (Participant 21, 22 Male, Lost Father)

The rituals participants performed in the virtual space could also be considered a form of communication with the deceased. These practices were often shaped by the religious background of the participants as they often perform religious rituals that honor their 
loved ones based on their religious beliefs. These ritualistic spaces play the role similar to that of a private shrine in the house.

Cause like in Korea I feel like, um, we need to commemorate death especially cause I think we do it cause we're Buddhist here, like my grandparents are Buddhists, I'm not Buddhist, but we put a lot of food on the table (Participant 17, 25 Female, Lost Grandfather)

Although private digital spaces can provide various channels through which mourners can engage in backstage grieving, we must emphasize the importance of having a well "balanced" digital frontstage and backstage grieving experience, where people are not completely withdrawn from the social space and "stuck" in private grieving alone.

\subsection{Control the negative grief narrative}

As a healthy mechanism of coping with grief, the bereaved individual often needs to deal with the negative emotions that emerge from their loss experience. The practice of "cognitive restructuring" in which people are exposed to memories of their negative experiences and then are encouraged to re-interpret them in a more functional manner, has been commonly employed in a number of treatment approaches for Prolonged Grief Disorder (PGD). By retelling stories of the deceased [56], grievers are able to better manage distressing emotions of past events (loss) and reassert their sense of control by engaging in reinterpreting the implications of the event and coming to terms of the loss and grief. The process of regaining control over the grief narratives involves constant cognitive re-framing and often requires support from mental health professionals.

Interestingly, a recurrent theme which emerged from our interviews suggested that albeit being an emotionally painful experience at times, our participants appreciated being urged as part of the LMH diary exercise to reflect on and confront the negative aspects of their past experiences with the deceased loved ones. While it is expected that grievers generally prefer to engage with positive memories and experience positive emotions when remembering the deceased, the interviews suggested that because participants were able to reflect more deeply about their negative emotions, it allowed them to better accept the negative memories as they were increasingly gaining control over their negative grief narrative. Overall, we identified two key aspects of backstage grieving which contribute to this effect. The first is related to the way private spaces help provide participants with a safe emotional outlet for their grief, allowing them to better identify and offload their negative emotions. We observed a number of instances where participants were active in expressing negative emotions which are generally difficult to disclose (such as those related to shame, regret and guilt). Participants reported being more expressive and honest about negative or conflicting memories, acknowledging that they are in a private space which is safe for "depositing" the memories (see section 4.4 for further discussion on this point). In some cases, participants reported that this process of disclosure had prompted more self-discovery, helping bring to light negative emotions that were previously unknown to them.

I find writing to be a wonderful means to, you know, to self reflect, but also to deal with some of the whatever emotions that might be hidden in your subconscious because they, they just come as you write. (Participant 23, 65 Female, Lost Father)

Some participants described this process of "offloading" their negative emotions as being relieving for them. Being able to express oneself emotionally, in particular in relation to stressful or traumatic experiences has been shown to be beneficial to emotional wellbeing and physical health [43]. A similar effect was reported by participants in our study.

People who don't have any tools right now and they're just keeping all of their [negative] emotions and all of their thoughts inside locked away until it's too painful and unbearable. So you need to be able to write and talk and, and get that out. (Participant 13, 35 Female, Lost Father)

Many people have resentments towards people that are past and didn't have time to work that out. I'm a fan of, you know, writing out that resentment and lighting a match to it. (Participant 9, 56 Female, Lost Father and Mother)

When you put things down, it relieves your mind of sort of mulling over those things. You don't keep thinking about them so much. If you write down your worries... you can stop your mind from going over and over and over the same material (Participant 8, 69 Female, Lost Mother)

The second aspect is related to how the storytelling activity helps encourage a more balanced reconstruction of their grief narrative, allowing participants to better accept the negative situations that occurred in the past. In this regard, the narrative activity in the backstage setting encourages a more balanced reappraisal of their loss experience. Participants indicated that this activity prompted them to further re-examine their shared experiences with the deceased in its entirety, empowering them to both celebrate the positive moments and also confront and come to terms with the negative aspects of their past actions and relationships.

I was in touch with some realities. I have no intention of saintify somebody just because they passed away. Nobody's a Saint. It's just the reality of there were things that were very good and things that were not. (Participant 6, 60 Female, Lost mother)

You can forgive yourself about your bad memories because you remember the good stuff, too... [This ] balanced the bad feelings that I still had about myself. I was not good enough for [her] or I was not present for her. These feelings are were not gone and I continue to feeling these things, but I think [the LMH] helped balance these feelings (I was not good enough in some situations) with good memories (Participant 20, 31 Female, Lost grandmother)

This aspect of backstage grieving exposed participants to a narrative of their loss through a balanced reconstruction of their experiences with their loved ones and asked them to elaborate in detail on the parts which had meaning for them [65]. This allows the participants to re-frame the negative aspects of their past and assume control over their continuing connections with the deceased, even when the memories are not positive. 


\subsection{Linking the past to the present}

Another important aspect of reflective backstage grieving is the private space it affords to mourners to explore past memories in the context of their present life. For instance, our participants explored things their deceased loved ones would have done or said in the current day-to-day life situations they are experiencing. Participants spoke of the struggle they are facing presently, as they seek comfort from the past conversations and stories with the deceased

Like last month I was just attacked on the street [..] it just made me think like[...] yeah, this happened to me. And he's like, wait, if I got through, you're going to get through it. He would know the perfect thing to tell me to calm me down (Participant 13, 35 Female, Lost Father)

This present-past emotional engagement can be seen as continuing lifelogging as discussed in Massimi and Baecker [50] which aptly maintained that "lifelogs do not become obsolete upon the death of the subject; rather, these databases can become afterlifelogs and support reflection, mourning, and commemoration". In fact, our participants went beyond "just" being a user of these databases; instead they become a co-creator of the lifelogging journey with the deceased, and continue the effort by blending past stories with their current life narratives. From the interaction design view point, "afterlifelogging" could move beyond ideas where users are viewed as passively absorbing past memories; instead backstage grieving is a negotiation between past and present, where users create, revise and evaluate the bond between their present selves and a certain memory fragment of the past.

This resonates strongly with the idea of "digital inheritance", tangible (e.g. smartphones, laptops, etc.) and intangible (e.g. digital media files, social media profiles) as described in Massimi and Baecker [50]. From our analysis, intangible inheritance is more than digital artefacts such as digital photos, as our participants continue to bond with the deceased to co-create their present experience by integrating the memories and stories of the past, through backstage grieving. In a way, it is as if they "inherited" new-found perspectives and ways of living from the deceased, which allows them to manage their grief and emotion. In the same way individuals can experience relief when this grieving emotion is brought to the frontstage in forms of religious and cultural practices (e.g. funeral) [81], our participants were able to better manage their emotion by bringing and integrating this grieving emotion into their present life.

I'm always thinking about my mom here [in Living Memory Home] and if I want to curse somebody out, I started thinking about my mom and I just walk away. (Participant 19, 52 Male, Lost mother)

While intangible inheritance such as large amounts of digital photographs may simply be deleted by the family members, this co-created experience, albeit intangible, is specifically selected and curated, and is strongly connected to the participants' on-going life. It hence bears personal touches and carries special meaning, compared to, say, thousands of digital photographs stored in a hard drive. Crucially, this is fundamentally consistent with Continuing Bond Theory [39] which argues that grieving focuses on developing and nurturing a new relationship with the deceased, through maintaining an inner representation of the deceased, as opposed to the dominant model that advocates for trying to "get over" or learning to "let go" of a loved one. Furthermore, our participants frequently expressed the feeling of "being with their loved ones", while they are experiencing grief backstage. In this instance, their deceased loved ones play the role of a "silent partner", nodding a silent approval to their comments and sharing their grief and happiness. This virtual connection perhaps helped shift the role of their loved ones from a "temporary communication partner" to more of an "permanent guardian angel" who is present with them in daily life.

It really helped me to explore my relationship with him and it kind of made me feel better that now I'm thinking of him and maybe he's like watching from above and he's like, Oh, okay, my granddaughter is thinking of me...I'm just thinking maybe he's glad that I'm thinking of him and maybe in the afterlife we can be friends.(Participant 17, 25 Female, Lost Grandfather)

When you're writing it's like you still feel the presence of that person if it makes any sense. Like, you know, I'm writing awesome things about my mom.... I know she feels like it wasn't spiritually, but like she's still right here. (Participant 19, 52 Male, Lost mother)

Research in reminiscence offers some hints on the importance of past-present emotional engagement on the mourner's emotional well-being. As a therapeutic intervention mostly targeted at older people, reminiscence is "using the recall of past events, feelings and thoughts to facilitate pleasure, quality of life, or adaptation to present circumstances" [16]. In a way similar to reminiscence, backstage grieving allows our participants to derive and construct meaning and happiness from the past, hence facilitating adaptation in the present when they are immersing in the past memory during bereavement. This grieving function allows people to redefine their difficult past memories as a resource and a basis for gratitude. However, one must be mindful that accessing past memories is not always beneficial, as reminiscence can have both positive and negative effects on mental well-being [88]. Some of our participants, while claiming that they did not notice negative or harmful effects of using the $\mathrm{LMH}$, cautioned against the potential risks for individuals who could get "addicted" to remembering the past or the dangers of triggering excessive grief when using the LMH for too long or without appropriate support.

The aspects that I think are potentially harmful from using memory home? Spending too much time in the memory home....just like other people tailor their activities when they get addicted to um, video game or whatever. (Participant 6, 60 Female, Lost mother)

I could absolutely see it for maybe a more fragile user without support, you could maybe provoke some or reactivate some [harmful] grief. But for me, I did not find it harmful. (Participant 9, 56 Female, Lost Father) 


\subsection{Digital Pensieve}

A key observation from our analysis points to the prevalence of using $\mathrm{LMH}$ as "digital pensieve ${ }^{1 "}$ to deposit the memories of the deceased. Not unlike a public memorial page, this backstage capturing and storing of memories allows the participant to mourn and honor the deceased by creating an enduring legacy or remembrance [26]. Unlike a memorial however, which aims to engage others in grieving the deceased, often leading to social support, we found that the desire of our participants to engage with backstage grieving - more specifically in recording information about the deceased - reflects the need for rituals to do something not only for the deceased, but also for themselves. These private mourning rituals "provide a structured response to insupportable feelings that, without outlet, might prove overwhelming" [31].

Death in the modern world is often accompanied by public bureaucratic rituals grievers have to conduct - with the bank, insurance companies, social security - most of which involve termination and closure of one thing or another, where any link of the deceased with the material world is severed. Therefore, the ritual of capturing digital memories serves as an important mechanism for our participants to cope with the sense of guilt and fear of forgetting the deceased, which underlines the unwillingness of many participants to "move on"; rather they actively seek to capture these memories and incorporate them in their ongoing life. Some participants explicitly outlined the benefit of LMH in getting rid of the emotional burden of forgetting the memories by keeping them safely in the virtual space.

People think that they're going to forget their loved one, but that it's taboo to talk about it. Oh, you're not over them yet. No. You know, like, no, no. And this is the proof because I'm writing for them regularly ...that I'm going to keep them, keep them alive in some form, you know? (Participant 9, 56 Female, Lost Parent)

Recording the information of the deceased may be a way to relieve the emotional pain the mourner experience, as "irrational" mal-adaptive thinking, e.g. "that one must hold on to the pain because it is the only way to remember the deceased ", could result in prolonged distress and depression [49]. Although the pervasiveness of social media means that a lot of personal information is now available for its users, social media data do not always capture information that reflects a person's life completely [73]. Especially for the older generations, social media information might be patchy or even not available. Our participants spoke of the importance of capturing personal information about the relationships with the deceased, key milestones and even the mundane aspects of daily life.

Those memories are still alive that we had such good times with her and everything else. She was like the, let's say the social butterfly of the family. [She was like] let's go to church, make sure you're ready for church...celebrating Christmas and holidays and Easter. (Participant 24, 66 Male, Lost Step Mother)

${ }^{1}$ a word borrowed from the children's novel "Harry Potter", which refers to a magical object used to review memories.
These stored memories, albeit sometimes containing private events which participants would not normally share at the frontstage, serve as a bank of "skeleton stories" which can be accessed later to tell stories and for reminiscence. These "skeleton stories" typically include: the moment of death, past events the participants experienced with the deceased, or past events they didn't know about but was told by others after the death, as well as hypothetical futures of the deceased had they not died. These memories curated backstage can be accessed to tell stories at frontstage, highlighting the dynamics and relationships between back and front stage grieving.

Interestingly, we observed that occasionally, storytelling can indeed be a backstage affair, directed not to other mourners (e.g. friends and families), instead to the deceased. For instance, it is not uncommon for Facebook users to post messages to the deceased [15]. Communication to the dead underlines the idea that relationships do not end because they are not physically present, and many people sense the presence of the dead and perceive conversations with them to be meaningful [40]. Perhaps this communication with the deceased can be characterized as a form of self-talk, which has been argued to help reduce anxiety, allowing the bereaved to fulfill their need to be part of a continuing relationship [33]. As a therapeutic approach, engaging in positive self-talk related to bereavement-specific themes could enhance self-esteem of the bereaved. It is claimed that even negative self-talk can be useful to help the bereaved explore problems which might lead to a more hopefully cognitive schema [17]. The participants reported feeling as if they were "having a conversation with the deceased" while writing in the online diary. These observations are in line with previous findings of research in digital grieving in which people see the deceased as a "virtual conversation partner", and that in people's mind, the communication may be "received". As Kern et. al. [37] put it, "the dead live in the virtual cloud, and can hear or read the messages from the living."

I think that it gave me the opportunity to see how I can use writing as a great way to speak with him. When I'm writing, I'm speaking, I use you or use me. It's almost like a conversation (Participant 23, 65 Female, Lost father).

So, I lost my mom in last November. The ritual of calling her daily was something that was probably one of the last things to get used to not doing...So the memory home, it still gives you that opportunity [to talk to her]... when something happens during the day or you're stressed or you just want to talk to someone that you normally would speak to. (Participant 6, 60 Female, Lost Mother).

Why are digital memories and storytelling important to the emotional well-being of the bereaved? Lule [46] asserts that people use narratives to "make sense of the world" (p. 273), our participants use narratives to make sense of their loss. Stroebe and Schut [72] suggested that coping with loss requires more than confronting one's grief, and that coping with loss involves active efforts to structure memories and thoughts as well as to regain mastery over one's life. This is also in line with Hagman's [27] claim that a key aspect of grieving is about restructuring of memories and representations that allow for a continuing connection with the lost person. This backstage memory collection provides materials for storytelling, 
where our participants relearn their world through rewriting the biographies of themselves and the deceased, re-creating the role, self and identity [85].

So I think [the memories] are challenged but not aggressive. It's like you have the opportunity to forget the bad memories because you remembered the good (Participant 20, 31 Female, Lost grandmother)

I think exploring relationships with someone else. Like whether it's negative or positive, whether it's sad or happy. I think it benefits both of you and I'm glad, like I kinda like feel like I formed a new relationship with him (Participant 17, 25 Female, Lost Grandfather)

\section{DISCUSSION}

As many aspects of our social lives are increasingly moving frontstage, thanks to the pervasiveness of social media, our findings shed some light onto some key aspects of backstage grieving in the digital age, an area which has been neglected in the digital bereavement literature. In this section, we present the implications of our findings, first by discussing the role of digital technology in backstage grieving, and then by examining how backstage grieving could support PGD. Finally, we highlight potential negative issues and risks such as the dangers of "getting stuck" in grief.

\subsection{Digital Technology in backstage Grief}

Within the digital grief literature, most studies have thus far looked at how existing frontstage tools have been appropriated to help users to create a social space for friends and families to commemorate the deceased. These studies have discussed for example, the role of online memorials and social media platforms in supporting users to "establish a grief community across time and space", where users can share their feelings about grief and exchange supportive messages with one another [70,87]. While this is clearly important, many of our participants expressed a considerable appreciation for an "emotionally safe" private space as part of their digital grieving experience. Our results underline the value of providing a virtual space for backstage grieving centered around the bereaved individual (as opposed to a frontstage space for friends and families); one that could be designed to provide a peaceful atmosphere to allow mourners to continue intimate bonds with the deceased, away from public spectatorship.

The LMH provides the users with the means to customize the visual aspect of their personal grieving space. In the context of backstage grieving, this personalization reflects the characteristics of the deceased loved one and the nature of their relationship with the mourners. While many online memorial sites offer a similar customization mechanism, it is aimed towards frontstage grieving, e.g decorating an online space for the community to visit to show empathy and support [12], instead of providing a soothing private space centered around the bereaved individual and their private thoughts as well as the intimate memories with the deceased. In creating these spaces for backstage grief, the results from our study also suggests the importance of providing mechanisms that allow users to control the more abstract environmental factors surrounding the space (e.g. ambient sound, relaxing scenery). Crucially, some of our participants also spoke about the influence of their cultural and religious backgrounds; as such, the design of this space needs to consider this sensitive nature of grieving practices.

As alluded to earlier, social media platforms are by and large designed to nurture a positive community and positive self-presentation $[21,44]$. When appropriated as a tool for grieving, social media may have failed to provide a space which protects the emotional vulnerability of users wishing to open up emotionally, particularly on deeply personal matters relating to immense grief and loss [69]. Through the private space afforded by the LMH, some participants cherished the liberation of being able to delve unreservedly into their emotions and memories, including negative ones, in their grieving experience. For some, this has led to self-discovery and the willingness to re-examine their relationship with the deceased. The backstage space allows users to deal with the loss in their own terms, helping them avoid the "coping paradox" that has been mentioned in grief studies on online social spaces (e.g. users being caught off guard by new distressing information about the deceased or being reminded of their presence too regularly while trying to cope, thus increasing the pain of their death instead of reducing it) [70] or feeling the social pressure to grieve before they are ready [86].

The interactions of the participants with the LMH had further reiterated the role digital technology could play in the creation and transference of digital inheritance. In prior studies this inheritance tends to be in the form of digital artifacts such as written content and photos of the deceased [50,60]. Such studies have highlighted the frontstage value of being able to archive, share and pass on stories and memories of the deceased for the community (e.g. as proposed on Facebook memorialize profiles [10]). However, in the backstage context, our study also hinted as to how technology might help pass on inheritances which are more intangible in nature, a notion which could be further explored. For example, participants had described how by reflecting on the memories of the past through the digital platform, they were able to bring forward the wisdom and values from their loved ones and apply them to the challenges and struggles they are encountering at present days.

Crucially, we acknowledge that grieving, online or offline, is a complex process, and some practices do not take place strictly in the backstage or frontstage sphere; rather they move back and forth in a fluid manner. Although our research goal is to explore backstage grieving, time and again our participants discussed their private bereavement in the wider context of digital grieving, quoting instances where public grieving suits certain emotional needs. This reflection provides some clues as to how public spaces for grieving could be designed to better facilitate the connection between front and backstage grieving. As an example, the current grieving experience on social media of our participants had left them lamenting about the intense casualization of online social support, in which very short messages can be exchanged quickly and effortlessly. The economic model fueling the growth of social media further reinforces the design for "fast and shallow" human interaction.

We therefore believe it would be important to adopt a "slow design" paradigm to support deeper interactions in digital grieving. The "slow design" movement is concerned with technology design that will endure and develop over time [30], through supporting 
experiences of expression, where slowness can create an appropriate pace of interaction that supports self-reflection. For instance, Odom et. al. 2014 studied how the past-paced nature of digital photo production can be "slowed down" to build users' anticipation and influence their perceptions of value and meaning when interacting with digital photos. In a similar vein, one should balance the "fast design" of frontstage online social support, and the "slow design" of backstage reflective grieving, e.g. online social media profiles of the deceased could be switched to a different mode which is more conducive to reflective relationships, rather than high volumes of "continuous stream" of rapid interactions.

\subsection{Backstage Grief in the Context of PGD and its Risks}

There is no denying that grieving often triggers certain negative emotions on the extreme spectrum, and social media implicit design rules generally shun negative emotions in favour of promoting a positive online community [4]. However, exposure to negative memories could be useful in encouraging the bereaved individuals to explore and confront their past challenges, a process which could lead to positive cognitive restructuring[17]. Indeed, grieving has been understood to be an experience of the loss in a repetitive and persistent manner, and it is believed that this "endless examination of how and why the loss occurred" [7] can help the bereaved to recognise and accept the new reality of their life.

Many of our participants mentioned that they developed a positive outlook and the acceptance of the loss by developing a new relationship with the deceased, through repeatedly engaging with the question prompts of the LMH, where they were asked to confront their negative emotions. This shows a potential of backstage grieving in alleviating the risk of PGD. Indeed, one of the primary diagnostic criteria of PGD is the pervasive yearning and longing for the deceased [68]. Backstage grieving can serve as a mechanism to transform this maladaptive yearning into healthy continued bond. Our question prompts were adapted from Neimeyer's book Techniques of Grief Therapy [56], focusing on meaning reconstruction through the process of corresponding with the deceased. Although our sample size is not big enough for us to verify the effect, the overall positive responses of the participants towards this guided backstage grief are worthy of future research.

The nature of an open digital shared space drives individuals to share contents mostly related to happy, positive and successful lifestyles [21], whereas death is often considered a taboo subject and hence disclosing grief could make people feel uneasy in a social context [5]. Even though many of our participants were open to sharing their grief in a digital public space, at least three participants specifically mentioned that the messages about their losses shared on social media required a certain level of curating and were rather superficial. As previous studies suggested, avoidance to confront negative emotions could lead to more intrusive thoughts of the deceased, poor health outcome and elevated risk of PGD in the long run [2]. While modern digital platforms emphasize connectivity and sharing, in the context of bereavement, our study points to the importance of offering a digital private space which can help provide a safe emotional outlet to facilitate the healthy engagement with negative narratives and emotions.
It is however, worth noting that the cognitive process of repetitive self reflection is closely related to another phenomenon, known as rumination, which has been empirically shown to lead to poor bereavement outcomes $[58,59]$. Bereavement-related rumination is characterised by persistent, chronic and passive focus on the occurrence, causes, and impacts of negative grief-related emotions and is shown to be a maladaptive process, and is conceptually related to prolonged grief [57]. What if this private space became a space where mourners got into a perpetual cycle of ruminating and brooding about the negative events? Furthermore, with the advances of new technologies, such as virtual reality, one must be cautious that such explicit interactions with the deceased in an highly immersive environment may not be desirable as the mourners may run the risk of being "stuck" in the past [53]. This will be an interesting future research direction, albeit one not without its ethical challenges.

It is therefore challenging to strive for a healthy design balance, lest users become adrift in the endless cycle of negative self-talks and grief-related rumination [3]. There are some directions to consider when designing digital technology to support private grieving. Firstly, there are different types of engagement with negative emotions. Those who are engaged with repetitive thoughts but with a purposeful processing of negative emotions and an end goal of resolution are more able to adapt positively. Those who are engaged with a ruminative process, characterized by repeated focus on negative emotions related to the death and what these emotions mean (self-talks such as “will I ever get over this?'), are more likely to get "stuck" and not progress towards finding a solution that lessens these negative feelings. It is crucial that design for digital grieving considers carefully how mourners interact and confront negative emotions. For instance, designers should be mindful of excessive interactions which "may take on a distinctly ruminative character, with repetitive focusing on how awful it is that [their] loved one died and how bad it feels to grieve"[53]. Secondly, we should acknowledge that mourners may have different personal circumstances and may be in different stages of the grieving process. Their interactions with negative emotions, either through frontstage or backstage channels, may evolve to allow them to adapt positively to the grieving process. For instance, [53] found a fairly robust inverse correlation between "making sense of why the death happened" and grief-related rumination, for those who had experienced the death more recently (less than one year). Apart from these, other factors such as the relationships between the mourner and the deceased may also play a role in the grieving process. For example, it is found that in the initial phase of bereavement, fathers are more likely to put their energies into practical issues than mothers [14]. In the case of the death of a child, their age, personality, and the circumstances of the death could determine a child's reaction to the loss of a sibling [13]. All these point to the diversity and complexity of grief, and hence the challenge of designing digital technologies for backstage grieving to mitigate the risk of getting "stuck".

Finally, it is also pointed out that by working through through negative emotions repeatedly, individuals come to terms with it, allowing them to "gradually tolerate increasing doses of distressing aspects of the event" [79]. Perhaps backstage grieving is more suitable for individuals who have moved on from the initial stage of grieving, and is more ready to form a new relationship with the deceased. Having this private space help them to move forward. 
For mourners who are still in the early stage of grief, frontstage oriented grieving might be more productive.

\section{CONCLUSION}

While digital technologies facilitate more social connectedness among individuals and their supporting communities, they also introduce challenges to intimacy and in-depth communications due to the simplification of social support into "liking" or brief comments on friends' posts $[23,89]$ and mediating intimacy through $24 / 7$ connectedness $[80,90]$. In the context of digital bereavement loss, such frontstage interactions, despite having a positive implication to an individual's well-being and facilitating a sense of belonging, do pose serious limitations in expressing ones' true feelings, establishing private and intimate connection with the deceased and asserting control over the grief narratives. While deceased loved ones are no longer physically present yet digitally "connected" to the mourners, our study uncovers the possibility to design and utilize digital technology to facilitate an in-depth and intimate connection with the deceased, a process we describe as backstage grieving.

Although the study allows us to further discuss the design opportunities for technologies that facilitate backstage grieving, a few limitations should be mentioned. First, given the importance of cultural differences, a larger sample size which include participants from different locations around the world will be beneficial to further validate the findings in our study. Second, the current design of LMH falls short in capturing the various cultural and religious aspects, which limits us from understanding how continuing bonds can be facilitated by including cultural or ritualistic mourning practices. Thirdly, the current study ran for a period of 1 month, and at least 6 months have passed after all our participants experienced the loss. This suggests that their approach to remembering and coping with grief could be quite different from the other phases such as pre-loss or early phase ( $<6$ month) of grief. Longer studies will be necessary to enrich our understanding of backstage grieving and continuing bonds digitally with the deceased loved ones through different phases of grief.

\section{ACKNOWLEDGMENTS}

The work carried out in this paper is supported by the R21 National Institute of Mental Health (NIMH) research grant (Grant number MH121886) as well as the R35 National Cancer Institute (NCI) research grant (Grant number CA197730). We would like to thank Madeline Rogers for supporting and monitoring our study participants.

\section{REFERENCES}

[1] Louis Bailey, Jo Bell, and David Kennedy. 2015. Continuing social presence of the dead: Exploring suicide bereavement through online memorialisation. New Review of Hypermedia and Multimedia 21, 1-2 (2015), 72-86.

[2] Amanda W Baker, Aparna Keshaviah, Arielle Horenstein, Elizabeth M Goetter, Christine Mauro, Charles F Reynolds III, Sidney Zisook, M Katherine Shear, and Naomi M Simon. 2016. The role of avoidance in complicated grief: a detailed examination of the grief-related avoidance questionnaire (GRAQ) in a large sample of individuals with complicated grief. Journal of Loss and Trauma 21, 6 (2016), 533-547.

[3] L Balmoral, WY Gong, and N O'Rourke. 2013. Reminiscence frequency predicts depressive symptoms but not life satisfaction 16-months later. In Poster session presented at the 121st annual convention of the American Psychological Association, Honolulu, HI.

[4] Erin D Basinger, Erin C Wehrman, and Kelly G McAninch. 2016. Grief communication and privacy rules: Examining the communication of individuals bereaved by the death of a family member. Fournal of Family Communication 16, 4 (2016), 285-302.

[5] Ernest Becker. 1997. The denial of death. Simon and Schuster.

[6] Paul A Boelen and Holly G Prigerson. 2007. The influence of symptoms of prolonged grief disorder, depression, and anxiety on quality of life among bereaved adults. European archives of psychiatry and clinical neuroscience 257, 8 (2007), 444-452.

[7] J Bolby. 1980. Attachment and loss: Vol 3. Loss: Sadness and depression.

[8] George A Bonanno and Stacey Kaltman. 2001. The varieties of grief experience. Clinical psychology review 21, 5 (2001), 705-734.

[9] Virginia Braun and Victoria Clarke. 2006. Using thematic analysis in psychology. Qualitative research in psychology 3, 2 (2006), 77-101.

[10] Jed R Brubaker and Vanessa Callison-Burch. 2016. Legacy contact: Designing and implementing post-mortem stewardship at facebook. In Proceedings of the 2016 CHI conference on human factors in computing systems. 2908-2919.

[11] Evan Carroll and John Romano. 2010. Your digital afterlife: When Facebook, Flickr and Twitter are your estate, what's your legacy? New Riders.

12] Dorthe Refslund Christensen and Kjetil Sandvik. 2013. Sharing death: Conceptions of time at a Danish online memorial site. Taming time, timing death: Social technologies and ritual 1 (2013), 99-118.

[13] Victor G Cicirelli. 1995. Loss of siblings through death. In Sibling Relationships Across the Life Span. Springer, 185-200.

[14] V Conway and J Feeney. 1997. Attachments and grief: A study of parental bereavement. Fournal of Family Studies 3 (1997), 36-42.

[15] Jocelyn M Degroot. 2012. Maintaining relational continuity with the deceased on Facebook. OMEGA-fournal of Death and Dying 65, 3 (2012), 195-212.

[16] Joanne McCloskey Dochterman and Gloria M Bulechek. 2004. Nursing interventions classification (NIC). Mosby Incorporated.

[17] Meredith Edgar-Bailey and Victoria E Kress. 2010. Resolving child and adolescen traumatic grief: Creative techniques and interventions. Fournal of Creativity in Mental Health 5, 2 (2010), 158-176.

[18] Nigel P Field and Charles Filanosky. 2009. Continuing bonds, risk factors for complicated grief, and adjustment to bereavement. Death Studies 34, 1 (2009), $1-29$.

[19] Nigel P Field, Eval Gal-Oz, and George A Bonanno. 2003. Continuing bonds and adjustment at 5 years after the death of a spouse. Fournal of consulting and clinical psychology 71, 1 (2003), 110.

[20] Pin Sym Foong and Denisa Kera. 2008. Applying reflective design to digital memorials. SIMTech'08 (2008)

[21] Donna Freitas. 2017. The happiness effect: How social media is driving a generation to appear perfect at any cost. Oxford University Press.

[22] Ann Fruhling and Sang Lee. 2005. Assessing the reliability, validity and adaptability of PSSUQ. AMCIS 2005 Proceedings (2005), 378.

[23] Howard Gardner and Katie Davis. 2013. The app generation: How today's youth navigate identity, intimacy, and imagination in a digital world. Yale University Press.

[24] Jim Gemmell, Lyndsay Williams, Ken Wood, Roger Lueder, and Gordon Bell. 2004. Passive capture and ensuing issues for a personal lifetime store. In Proceedings of the the 1st ACM workshop on Continuous archival and retrieval of personal experiences. 48-55.

[25] Emily Getty, Jessica Cobb, Meryl Gabeler, Christine Nelson, Ellis Weng, and Jeffrey Hancock. 2011. I said your name in an empty room: grieving and continuing bonds on facebook. In Proceedings of the SIGCHI Conference on human factors in computing systems. 997-1000.

[26] Rebecca Gulotta, David B Gerritsen, Aisling Kelliher, and Jodi Forlizzi. 2016. Engaging with death online: An analysis of systems that support legacy-making, bereavement, and remembrance. In Proceedings of the 2016 ACM Conference on Designing Interactive Systems. 736-748.

[27] George Hagman. 1995. Mourning: A review and reconsideration. International Journal of Psycho-Analysis 76 (1995), 909-925.

[28] Christopher Hall. 2014. Bereavement theory: Recent developments in our understanding of grief and bereavement. Bereavement Care 33, 1 (2014), 7-12.

[29] Elizabeth Hallam and Jenny Hockey. 2001. Death, memory and material culture. Unknown Publisher.

[30] Lars Hallnäs and Johan Redström. 2001. Slow technology-designing for reflection. Personal and ubiquitous computing 5, 3 (2001), 201-212.

[31] Joan D Hedrick. 1995. Harriet Beecher Stowe: A Life. Oxford University Press.

[32] R Hertz. 2004. A Contribution to the Study of the Collective Representation of Death. Death, Mourning and Burial. A Cross-Cultural Reader.

[33] Min-Tao Hsu, David L Kahn, Der-Heuy Yee, and Wei-Lun Lee. 2004. Recovery through reconnection: A cultural design for family bereavement in Taiwan. Death studies 28,8 (2004), 761-786.

[34] John Dixon Hunt. 2001. Come into the garden, Maud": Garden art as a privileged mode of commemoration and identity. Places of commemoration: Search for identity and landscape design. Washington, DC: Dumbarton Oaks (2001).

[35] Melissa D Irwin. 2015. Mourning 2.0-Continuing bonds between the living and the dead on Facebook. OMEGA-fournal of Death and Dying 72, 2 (2015), 119-150. 
[36] Elaine Kasket. 2012. Continuing bonds in the age of social networking: Facebook as a modern-day medium. Bereavement Care 31, 2 (2012), 62-69.

[37] Rebecca Kern, Abbe E Forman, and Gisela Gil-Egui. 2013. RIP: Remain in perpetuity. Facebook memorial pages. Telematics and Informatics 30, 1 (2013), 2-10.

[38] David Kirk and Richard Banks. 2008. On the design of technology heirlooms. SIMTech'08 (2008).

[39] Dennis Klass, Phyllis R Silverman, and Steven Nickman. 2014. Continuing bonds: New understandings of grief. Taylor \& Francis.

[40] D Klass and Tony Walter. 2001. Processes of grieving: how bonds are continued. In Handbook of Bereavement Research: Consequences, Coping, and Care. American Psychological Association, 431-448.

[41] Sara Koktan. 2017. Death 2.0: Facebook memorial pages. Technical Communication Capstone Course 15 (2017).

[42] Elisabeth Kübler-Ross and David Kessler. 2005. On grief and grieving: Finding the meaning of grief through the five stages of loss. Simon and Schuster.

[43] Thomas A Langens and Julia Schüler. 2007. Effects of written emotional expression: The role of positive expectancies. Health Psychology 26, 2 (2007), 174.

[44] Roselyn J Lee-Won, Minsun Shim, Yeon Kyoung Joo, and Sung Gwan Park. 2014 Who puts the best "face" forward on Facebook?: Positive self-presentation in online social networking and the role of self-consciousness, actual-to-total Friends ratio, and culture. Computers in Human Behavior 39 (2014), 413-423.

[45] Brett T Litz, Yonit Schorr, Eileen Delaney, Teresa Au, Anthony Papa, Annie B Fox, Sue Morris, Angela Nickerson, Susan Block, and Holly G Prigerson. 2014. A randomized controlled trial of an internet-based therapist-assisted indicated preventive intervention for prolonged grief disorder. Behaviour research and therapy 61 (2014), 23-34.

[46] Jack Lule. 1990. Telling the story of story: Journalism history and narrative theory. American fournalism 7, 4 (1990), 259-274.

[47] Marie Lundorff, Helle Holmgren, Robert Zachariae, Ingeborg Farver-Vestergaard, and Maja O'Connor. 2017. Prevalence of prolonged grief disorder in adult bereavement: A systematic review and meta-analysis. Fournal of Affective Disorders 212 (2017), 138-149.

[48] Cristiano Maciel and V Pereira. 2013. Digital legacy and interaction. Heidelberg, Germany (2013).

[49] Ruth Malkinson and Therese Brask-Rustad. 2013. Cognitive behavior couple therapy-REBT model for traumatic bereavement. Fournal of Rational-Emotive \& Cognitive-Behavior Therapy 31, 2 (2013), 114-125.

[50] Michael Massimi and Ronald M Baecker. 2010. A death in the family: opportunities for designing technologies for the bereaved. In Proceedings of the SIGCHI conference on Human Factors in computing systems. 1821-1830.

[51] Michael Massimi and Andrea Charise. 2009. Dying, death, and mortality: towards thanatosensitivity in HCI. In CHI'09 Extended Abstracts on Human Factors in Computing Systems. 2459-2468.

[52] Rhonda N McEwen and Kathleen Scheaffer. 2013. Virtual mourning and memory construction on Facebook: Here are the terms of use. Bulletin of Science, Technology \& Society 33, 3-4 (2013), 64-75.

[53] Scott T Michael and CR Snyder. 2005. Getting unstuck: The roles of hope, finding meaning, and rumination in the adjustment to bereavement among college students. Death studies 29, 5 (2005), 435-458.

[54] Daniel Miller and Fiona Parrott. 2009. Loss and material culture in South London. Journal of the Royal Anthropological Institute 15, 3 (2009), 502-519.

[55] Wendy Moncur and David Kirk. 2014. An emergent framework for digital memorials. In Proceedings of the 2014 conference on Designing interactive systems. 965-974.

[56] Robert A Neimeyer. 2012. Retelling the narrative of the death. Techniques of grief therapy (2012), 86-90.

[57] Susan Nolen-Hoeksema. 2001. Ruminative coping and adjustment to bereavement. (2001).

[58] Susan Nolen-Hoeksema and Christopher G Davis. 1999. " Thanks for sharing that": Ruminators and their social support networks. Fournal of personality and social psychology 77, 4 (1999), 801.

[59] Susan Nolen-Hoeksema, Judith Larson, and Judith M Larson. 2013. Coping with loss. Routledge.

[60] William Odom, Richard Banks, David Kirk, Richard Harper, Siân Lindley, and Abigail Sellen. 2012. Technology heirlooms? Considerations for passing down and inheriting digital materials. In Proceedings of the SIGCHI Conference on Human Factors in computing systems. 337-346.

[61] William Odom, Richard Harper, Abigail Sellen, David Kirk, and Richard Banks 2010. Passing on \& putting to rest: understanding bereavement in the context of interactive technologies. In Proceedings of the SIGCHI conference on Human Factors in computing systems. 1831-1840.

[62] William Odom, Daisuke Uriu, David Kirk, Richard Banks, and Ron Wakkary. 2018. Experiences in designing technologies for honoring deceased loved ones. Design Issues 34, 1 (2018), 54-66.

[63] William T Odom, Abigail J Sellen, Richard Banks, David S Kirk, Tim Regan, Mark Selby, Jodi L Forlizzi, and John Zimmerman. 2014. Designing for slowness, anticipation and re-visitation: a long term field study of the photobox. In Proceedings of the SIGCHI Conference on Human Factors in Computing Systems. 1961-1970.

[64] Gary M Olson and Judith S Olson. 2000. Distance matters. Human-computer interaction 15, 2-3 (2000), 139-178.
[65] Tuvia Peri, Ilanit Hasson-Ohayon, Sharon Garber, Rivka Tuval-Mashiach, and Paul A Boelen. 2016. Narrative reconstruction therapy for prolonged grief disorder-Rationale and case study. European fournal of Psychotraumatology 7, 1 (2016), 30687.

[66] Holly G Prigerson, Andrew J Bierhals, Stanislav V Kasl, Charles F Reynolds, M Katherine Shear, Nancy Day, Laurel C Beery, Jason T Newsom, and Selby Jacobs. 1997. Traumatic grief as a risk factor for mental and physical morbidity. American journal of psychiatry 154 (1997), 616-623.

[67] Holly G Prigerson, Mardi J Horowitz, Selby C Jacobs, Colin M Parkes, Mihaela Aslan, Karl Goodkin, Beverley Raphael, Samuel J Marwit, Camille Wortman, Robert A Neimeyer, et al. 2009. Prolonged grief disorder: Psychometric validation of criteria proposed for DSM-V and ICD-11. PLoS medicine 6, 8 (2009).

[68] Holly G Prigerson, Lauren C Vanderwerker, and Paul K Maciejewski. 2008. A case for inclusion of prolonged grief disorder in DSM-V. (2008).

[69] Lin Qiu, Han Lin, Angela K Leung, and William Tov. 2012. Putting their best foot forward: Emotional disclosure on Facebook. Cyberpsychology, Behavior, and Social Networking 15, 10 (2012), 569-572.

[70] Kelly R Rossetto, Pamela J Lannutti, and Elena C Strauman. 2015. Death on Facebook: Examining the roles of social media communication for the bereaved. Journal of Social and Personal Relationships 32, 7 (2015), 974-994.

[71] Corina Sas, Miriam Schreiter, Monika Büscher, Fiorenza Gamba, and Alina Coman. 2019. Futures of digital death: Past, present and charting emerging research agenda.

[72] Henk Schut, Margaret Stroebe. 1999. The dual process model of coping with bereavement: Rationale and description. Death studies 23, 3 (1999), 197-224.

[73] Victoria Schwanda Sosik, Xuan Zhao, and Dan Cosley. 2012. See friendship, sort of: How conversation and digital traces might support reflection on friendships. In Proceedings of the ACM 2012 conference on Computer Supported Cooperative Work. 1145-1154.

[74] Clive Seale. 1998. Constructing death: The sociology of dying and bereavement. Cambridge University Press.

[75] Wan Jou She. 2018. Toward Empowerment: screening prolonged grief disorder in the first six months of bereavement. Ph.D. Dissertation. PhD Thesis, Department of Industrial Design, Eindhoven University of ....

[76] Carla J Sofka. 1997. Social support" internetworks," caskets for sale, and more: Thanatology and the information superhighway. Death Studies 21, 6 (1997), 553-574.

[77] Margaret Stroebe and Henk Schut. 2005. To continue or relinquish bonds: A review of consequences for the bereaved. Death studies 29, 6 (2005), 477-494.

[78] Margaret S Stroebe, Georgios Abakoumkin, Wolfgang Stroebe, and Henk Schut. 2012. Continuing bonds in adjustment to bereavement: Impact of abrupt versus gradual separation. Personal Relationships 19, 2 (2012), 255-266.

[79] Rosemary Tait and Roxane Cohen Silver. 1989. Coming to terms with major negative life events. Unintended thought (1989), 351-382.

[80] Sherry Turkle. 2017. Alone together: Why we expect more from technology and less from each other. Hachette UK.

[81] Ronny E Turner and Charles Edgley. 1976. Death as theater: A dramaturgical analysis of the American funeral. Sociology \& Social Research (1976).

[82] Elise Van den Hoven, Wina Smeenk, Hans Bilsen, Rob Zimmermann, Simone de Waart, and Koen van Turnhout. 2008. Communicating commemoration. Proc. of SIMTech 8 (2008).

[83] Anna JM Wagner. 2018. Do not click "like" when somebody has died: The role of norms for mourning practices in social media. Social Media+ Society 4, 1 (2018), 2056305117744392.

[84] Birgit Wagner and Andreas Maercker. 2007. A 1.5-year follow-up of an internetbased intervention for complicated grief. Journal of Traumatic Stress: Official Publication of The International Society for Traumatic Stress Studies 20, 4 (2007), 625-629.

[85] Tony Walter. 1996. A new model of grief: Bereavement and biography. Mortality 1,1 (1996), 7-25.

[86] Tony Walter. 2015. New mourners, old mourners: Online memorial culture as a chapter in the history of mourning. New Review of Hypermedia and Multimedia 21, 1-2 (2015), 10-24.

[87] Tony Walter, Rachid Hourizi, Wendy Moncur, and Stacey Pitsillides. 2012. Does the internet change how we die and mourn? Overview and analysis. OMEGAJournal of Death and Dying 64, 4 (2012), 275-302.

[88] Jeffrey Dean Ed Webster and Barbara K Haight. 2002. Critical advances in reminiscence work: From theory to application. Springer Publishing Co.

[89] Emily Weinstein and Katie Davis. 2015. Connecting'round the clock: mobile phones and adolescents' experiences of intimacy. In Encyclopedia of mobile phone behavior. IGI Global, 937-946.

[90] Emily C Weinstein and Robert L Selman. 2016. Digital stress: Adolescents' personal accounts. new media \& society 18, 3 (2016), 391-409.

[91] Julie Loebach Wetherell. 2012. Complicated grief therapy as a new treatment approach. Dialogues in clinical neuroscience 14, 2 (2012), 159.

[92] Kate Woodthorpe. 2010. Private grief in public spaces: Interpreting memorialisation in the contemporary cemetery. In The Matter of Death. Springer, 117-132. 